\title{
Canadian Association of Neuroscience Review: Development and Plasticity of the Auditory Cortex
}

\author{
Jun Yan
}

\begin{abstract}
The functions of the cerebral cortex are predominantly established during the critical period of development. One obvious developmental feature is its division into different functional areas that systematically represent different environmental information. This is the result of interactions between intrinsic (genetic) factors and extrinsic (environmental) factors. Following this critical period, the cerebral cortex attains its adult form but it will continue to adapt to environmental changes. Thus, the cerebral cortex is constantly adapting to the environment (plasticity) from its embryonic stages to the last minute of life. This review details important factors that contribute to the development and plasticity of the auditory cortex. The instructive role of thalamocortical innervation, the regulatory role of cholinergic projection of the basal forebrain and the potential role of the corticofugal modulation are presented.
\end{abstract}

\begin{abstract}
RÉSUMÉ: Développement et plasticité du cortex auditif. Les fonctions du cortex cérébral sont établies en grande partie pendant une période critique du développement. Sa division en différentes zones fonctionnelles, qui représentent systématiquement différentes informations environnementales, résulte d'interactions entre des facteurs intrinsèques (génétiques) et des facteurs extrinsèques (environnementaux). Après cette période critique, le cortex cérébral atteint sa forme adulte. Il va cependant continuer à s'adapter aux changements environnementaux. Ainsi, le cortex cérébral est en adaptation constante à l'environnement (la plasticité), de la phase embryonnaire jusqu'aux derniers instants de la vie. Cette revue décrit en détail les facteurs importants qui contribuent au développement et à la plasticité du cortex auditif. Le rôle informatif de l'innervation thalamocorticale, le rôle régulateur des projections cholinergiques du cerveau antérieur et le rôle potentiel de la modulation corticofuge sont présentés.
\end{abstract}

Can. J. Neurol. Sci. 2003; 30: 189-200

From early development to adulthood, the brain is continuously shaped by the interactions of genetic and environmental factors. Neural plasticity allows the brain to adapt to continuous changes in our environment. It takes place in our everyday life and determines the functional organization and reorganization of the brain. Abnormalities in such processing may result in brain dysfunction and strongly impact the quality of life as seen in Rett Syndrome and Alzheimer's disease.

One of the most intriguing features of the neocortex is its distinct parcellation or division into various functional districts such as auditory and other sensory areas where environmental information is systematically represented. ${ }^{1-6}$ This representation is subject to continuous alteration or plasticity throughout the life cycle as previously observed., ${ }^{1,4-13}$ The mechanisms underlying the ontogeny of cortical specification or identities, such as the tonotopy of the auditory cortex or the best frequency of auditory cortical neurons and its plasticity, have been challenging issues.

There is increasing evidence that a number of intrinsic and extrinsic factors are involved in the formation of cortical specification. During early development, a variety of molecular guidance cues intrinsic to the neocortex contribute to the specification of early regional identities of the neocortex; this occurs even before the arrival of thalamocortical sensory inputs. ${ }^{14,15}$ However, the development of the functional specification or identity of the neocortex is largely reliant upon thalamocortical sensory inputs. ${ }^{14,16}$ During adulthood, the plasticity of functional identities of the cerebral cortex also relies on thalamocortical inputs, specifically, sensory input. ${ }^{9,17}$ The thalamocortical input, therefore, is a critical factor for both the development and plasticity of the functional specification or

From the Department of Physiology and Biophysics, Neuroscience Research Group, Faculty of Medicine, University of Calgary, Calgary, Alberta, T2N 4N1, Canada. Received November 13, 2002. AcCePted in final form March 13, 2003. Reprint requests to: Jun Yan, Department of Physiology and Biophysics, Neuroscience Research Group, Faculty of Medicine, University of Calgary, 3330 Hospital Drive, N.W., Rm 193B, Calgary, Alberta, T2N 4N1, Canada 
identity of the neocortex. It has been established, however, that the normal development and plasticity of the neocortex also requires cortical cholinergic modulation. ${ }^{9,18}$ Recent progress in the study of corticofugal modulation also suggests that the neocortex is actively involved in the central plasticity through the corticofugal feedback loops. ${ }^{13,19}$

This review will focus upon the dynamic changes that occur in the auditory cortex from perinatal period to adulthood. The ongoing contributions of thalamocortical innervation, cholinergic regulation and corticofugal modulation to the plasticity of the auditory cortex (Figure 1) will be emphasized.

\section{INSTRUCTIVE ROLE OF THALAMOCORTICAL INPUTS DURING CORTICAL DEVELOPMENT}

Although there is no definitive point at which the cortex attains maturity, that is, when environmental information is systematically represented, many studies have indicated that a critical period for sensory development does exist in all species. ${ }^{20}$ The critical period refers to a rapid developmental period in animal life. During this period, the functional areas of the neocortex are quickly specified; cortical identities, such as threshold and frequency tuning of the auditory cortex ${ }^{21}$ and monocular spatial vision of the visual cortex, are developed. ${ }^{22}$ Sensory function generally reaches maturity after the critical period. Some functions are quickly established while others require a longer period. As shown by the study on the development of the kitten's auditory cortex, cortical neurons mature in an exponential manner during the critical period (Figure 2). ${ }^{21}$

There is increasing evidence that cortical development is controlled by genetic factors before the critical period as suggested by studies in the prenatal period in rodents. ${ }^{14,15,23-25}$ Several specific regions in the neocortex can be identified at the level of gene expression. ${ }^{14,15}$ The strongest evidence is revealed by the areal pattern of gene expression in the neocortex of the mouse lacking the thalamocortical afferents. For example, region-specific gene expression normally appears in Mash-1 or Gbx-2 mutant mice that fail to develop thalamocortical projections to the cortex. ${ }^{26,27}$ These findings suggest that the early-specified areas of the neocortex are created independently from thalamocortical innervation. Such cortical areas identified by gene expression during early development do not exhibit a clear border; ${ }^{27}$ it is still unknown whether or not they are directly associated with final sensory maps.

A sequence of events occurring during the critical period of development is responsible for the specification of cortical areas and the development of cortical identities. The key event is the arrival of thalamocortical inputs. ${ }^{14,28}$ Upon the arrival of thalamocortical fibers at layer 4 of the neocortex, specific functional areas become detectable. ${ }^{25}$ At the initial stage, i.e., before the maturation of the sensory organs or before the animal is able to acquire sensory experience, the specification of cortical areas is dominated by spontaneous activities of thalamocortical inputs. In other words, development of the cortical specification is independent from sensory cues at this stage. Such activitydependent cortical specification is predominantly documented by studies of the visual cortex. For example, some aspects of the specification of the visual cortex, such as ocular dominance, are already presented prior to any visual cues. ${ }^{29}$ In the mature auditory cortex, sound frequencies are systematically represented as tonotopic maps. It is not yet known whether there is a precursor of the cochleotopic specification in the auditory area of the neocortex before auditory experience. If the early development of the auditory cortex shares the same mechanism as that of the visual cortex, the cochleotopic specification should also be established with the spontaneous activity of the thalamocortical inputs, i.e., before sound-driven activity.

Although some cortical specifications may occur before sensory experience, sensory-driven activities appear to be decisive for the formation of the final tonotopic maps in the auditory cortex, that is, the reshaping and refinement of the cortical specification. This is clearly demonstrated by studies that examine the tonotopic organization of the auditory cortex after either elimination or augmentation of auditory inputs in neonatal animals. It has been shown that the deprivation of particular frequency band inputs of the cochlea drastically alters the mature tonotopic representation in the auditory cortex. The receptive fields of these cortical neurons that originally tune to the deprived frequency move or shift to the neighboring frequency. ${ }^{30,31}$ On the other hand, over-exposure to a particular sound leads to the expansion of the representation of such sound in the auditory cortex. ${ }^{32}$ Such frequency-specific change in cortical tonotopy following neonatal alteration of auditory inputs provides insights into the importance of the auditory experience in shaping the cortical organization.

Merzenich and his colleagues ${ }^{33,34}$ recently presented strong evidence that sensory experience play a vital role in early development of specific area and frequency identity of the auditory cortex. The sound-driven unit firing of cortical neurons in postnatal rats can be detected as early as postnatal day 13 and shows very broad frequency tuning and high threshold. Following an increase in age, the frequency tuning of initially broadly-tuned neurons became sharper and their threshold decreased. This suggests that the frequency selectivity and the sensitivity of cortical neurons increase following the accumulation of sensory experience and the maturation of thalamocortical inputs. These findings are consistent with those found in cats, which indicates that the specific area representing sound frequency information is progressively shaped into adult form. ${ }^{21}$ Furthermore, early exposure to particular sounds leads to the acceleration of cortical maturation and the expansion of the cortical representation of these particular sound frequencies. ${ }^{33} \mathrm{In}$ contrast, exposure to white noise covering all frequencies during the first postnatal month disrupts the systematical tonotopic representation of the auditory cortex and degrades the frequency selectivity of cortical neurons. Such results cannot be seen if the exposure is later than postnatal day $30 .{ }^{34}$ These data strongly suggest that the tonotopic organization and frequency identities of the auditory cortex are developed largely based on the auditory cues from distinct thalamocortical inputs during the critical period. This also implies that the thalamocortical input competition rule found in the ocular dominance plasticity in the visual cortex 29,35 is shared in the development of the auditory cortex. Sound-driven activities of the thalamocortical inputs apparently determine the final form of the functional specification of the auditory cortex and the functional identity of cortical neurons. 


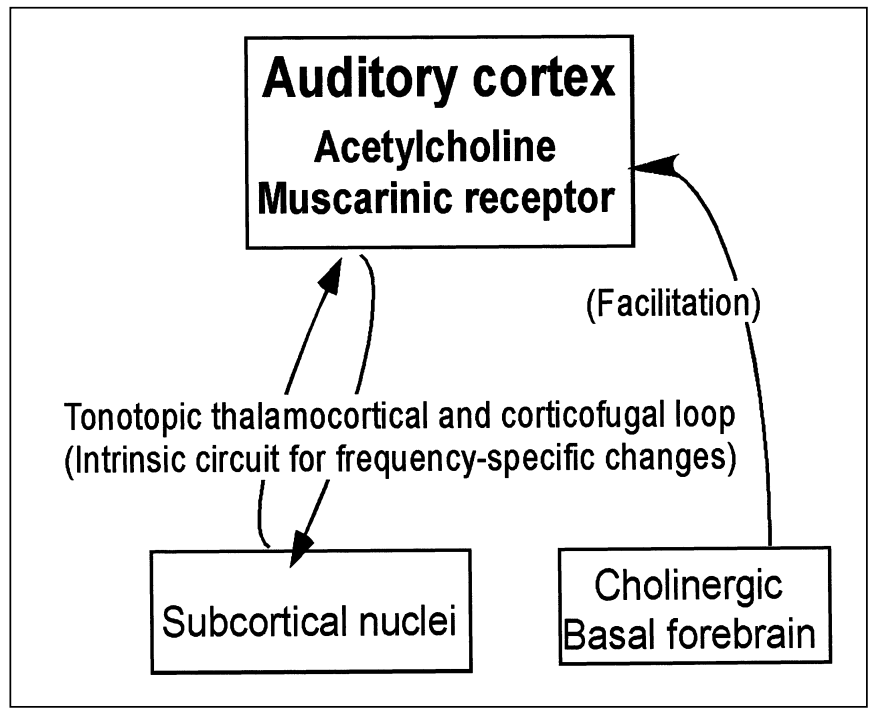

Figure 1: A schematic of the neural circuit underlying the frequencyspecific plastic changes in the central auditory system. Ascending and descending projections form tonotopic feedback loops for frequencyspecific plasticity in the central auditory system. The cholinergic projection from the basal forebrain augments or accelerates this frequency-specific plasticity in the auditory cortex.

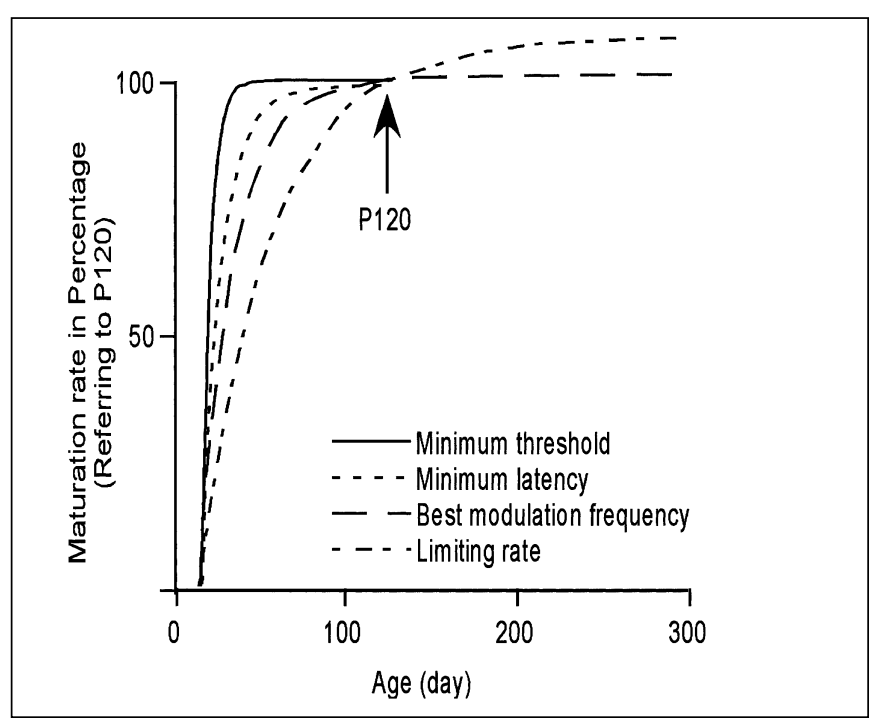

Figure 2: The time course of maturation in different cortical response properties of the cat. It is clearly shown that the maturation of cortical response properties increase exponentially but each of them attains adult responses within a different time frame. P120: postnatal day 120. (Based on data from Eggermont, Audit Neurosci 1996;2:309-327.)

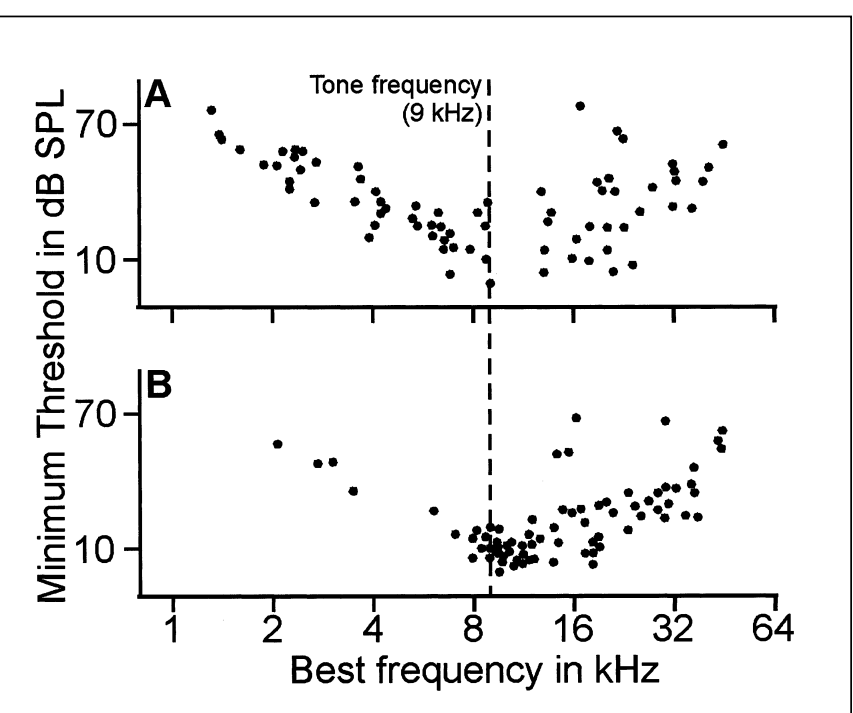

Figure 4: Minimum thresholds are plotted as the function of best frequencies of the neurons evenly sampled from entire primary auditory cortex of a normal rat (A) and of a rat that received the electrical stimulation of the basal forebrain paired with a tone of $9 \mathrm{kHz}(B)$. The electrical stimulation largely modifies the frequency representation of the primary auditory cortex; many more cortical neurons tune to about $9 \mathrm{kHz}$, i.e., the frequency of paired tone. (Reprinted with permission from Kilgard MP, Merzenich MM. Cortical map reorganization enabled by nucleus basalis activity. Science 1998; 279(5357): 1714-1718. Copyright 1998 American Association for the Advancement of Science.) 


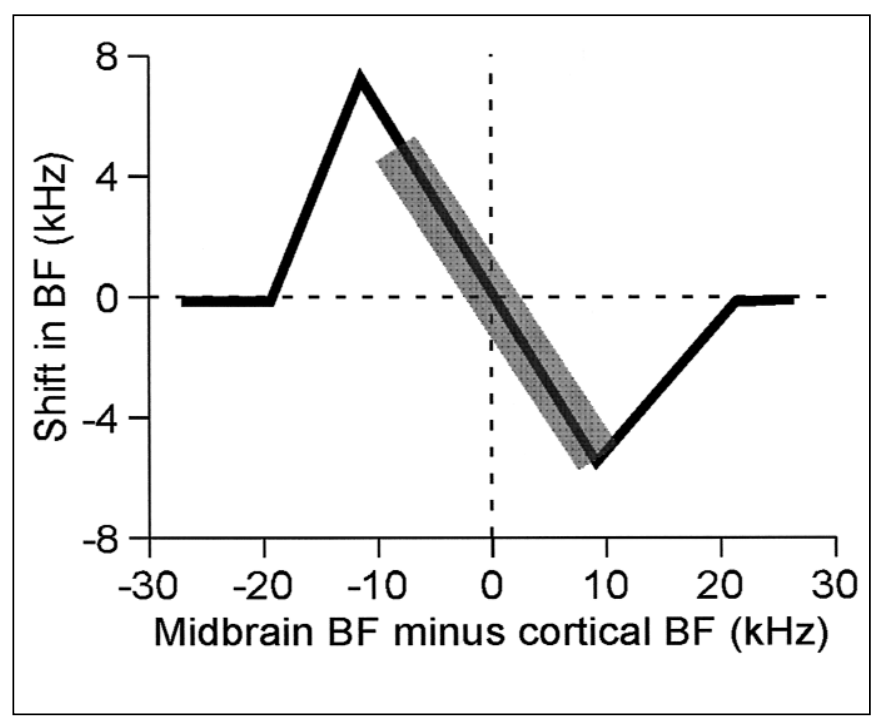

Figure 5: Schematics of shifts in the best frequency of midbrain neurons following focal cortical stimulation. Cortical activation shifts the best frequency $(B F)$ of midbrain neurons upward when the stimulated cortical $B F$ is higher than the recorded midbrain $B F$ and downward when the cortical BF is lower than the midbrain BF; cortical activation shifts midbrain BFs toward the BF of cortical neurons. The shift in midbrain $B F$ is linearly correlated to the $B F$ difference when the difference between midbrain and cortical BFs is between -12 to $10 \mathrm{kHz}$. (Yan \& Ehret, Euro J Neurosci 2002;416(1):119-128). Interestingly, the pattern of shifts in cortical BFs evoked by paired stimuli of basal forebrain and tone is similar to the pattern evoked by focal cortical stimulation (grey area, Zhang \& Yan, unpublished data).

Significantly, the unusual tonotopic organization of the auditory cortex following the alteration of the auditory inputs does not necessarily imply that the functional changes occur solely at the auditory cortex or thalamocortical projections. When the auditory inputs are altered, the thalamocortical projections morphologically appear normal ${ }^{36}$ and the changes in the functional organization are also seen below the thalamus. ${ }^{37,38}$ The elimination or augmentation of the auditory inputs suggests that the content of thalamocortical inputs is altered. Such an alteration determines the final organization of the auditory cortex.

Other important evidence, obtained from the cross-modal plasticity studies, clearly demonstrates the influence of thalamocortical inputs in the specification or differentiation of the neocortex. In cross-modal animals, redirection of afferents of one sensory modality into another during early life leads to significant changes in functional connections within the neocortex and complete changes in cortical response properties to natural stimuli. For example, redirection of visual inputs to the auditory thalamus of the ferret in the first postnatal day reorganizes the horizontal connections in the auditory cortex; the neurons in the auditory cortex eventually respond to visual stimulation in a manner comparable to the neurons in the visual cortex. $^{39,40}$

Taken in summary, these studies reveal that thalamocortical inputs instruct and/or promote the development of the specification and identity of the auditory cortex.

\section{ChOlINERgic REgulation OF EARLY CORTICAL DEVELOPMENT}

Recent progress in the ontogeny of the neocortex indicates that normal development or maturation of the cortex relies not only on thalamocortical inputs to the neocortex but also on neuromodulatory systems in the brain. The impact of the cholinergic system is very noticeable; cortical acetylcholine has recently been found to play an important role in many aspects of cortical development. ${ }^{18,41,42}$ Unlike the intrinsic and extrinsic factors that control the early development of the neocortex, acetylcholine is likely a permissive factor for the early development and plasticity of the neocortex.

It has long been known that acetylcholine serves as a neuromodulator rather than a neurotransmitter in the central nervous system. The source of primary cholinergic afferents to the cortex in mammals mostly originates from the nucleus basalis of the basal forebrain. ${ }^{43,44}$ In some species, additional cholinergic innervation comes from intracortical neurons..$^{45}$ These intrinsic neurons, however, are absent in some species such as the mouse. ${ }^{46}$ Although cholinergic neurons are generated at about embryonic days 11 to 16 depending on the species, cholinergic innervation of the neocortex begins in the perinatal period. The examination of the length and branching of the axons and the number of varicosities per unit length of axon of the rat brain with immunostaining choline acetyltransferase indicates that cholinergic innervation of the neocortex is already presented at birth but that the number of cholinergic fibers is very low. The density of cholinergic fibers, and numbers of varicosities and branches are quickly increased in the cortex during the first two weeks after birth. Adult values are attained at postnatal day $16 .{ }^{47}$

Interestingly, the basal forebrain cholinergic fibers begin innervating cortical neurons at almost the same time as thalamocortical fibers arrive in the cortex. Cholinergic activities in the cortex are at a higher level in the first two to three weeks, the most dynamic period of neuronal maturation and synaptic formation in the cortex. ${ }^{28,48-52}$ Discounting mere coincidence, what can this suggest? Some studies have examined the change in cortical morphorgenesis by the elimination of the cortical cholinergic inputs. Using electrolytic lesions or other approaches to destroy the basal forebrain at birth, these studies have shown that ablation of the cholinergic innervation of the neonatal cortex leads to a number of significant changes in cortical morphogenesis. These changes include smaller soma size, shorter apical and basal dendritic branches, unclear boundaries in supergranular layers, abnormal pattern formation in layer IV of the cortex, abnormal cortical connectivity and altered distribution of thalamocortical projections in the neocortex. ${ }^{53-55}$ Such changes in cortical morphogenesis should lead to practical deficits in the function of the neocortex. An additional fact of considerable relevance is that the changes in cortical morphorgenesis are accompanied by abnormal performance of behavioral tasks. ${ }^{55}$ Unfortunately, there are no reports on the physiological changes of the neocortex following the neonatal ablation of cortical cholinergic innervation.

In the auditory cortex of rats, the acetylcholinesterase activity is transiently expressed in the early postnatal period. Transient 
acetylcholinesterase activity occurs mainly in layer IV and deep layer III of the auditory cortex. With histochemical technique, acetylcholinesterase activity can be detected at as early as postnatal day 3 in rat, reaching peak levels at postnatal days 8 to 10 and returning to adult levels at postnatal day $23 .{ }^{56}$ Furthermore, lesion of the medial geniculate body results in deprivation of the thalamocortical inputs and largely reduces the acetylcholinesterase activity in the auditory cortex. ${ }^{56}$ These findings suggest that the time course of cholinergic regulation in the auditory cortex matches the critical period of cortical development and implicate that the cholinergic regulation is associated with the development of thalamocortical innervation. Combined with the findings of cholinergic role in the auditory plasticity of adult animals (see details below), the speculation is that cholinergic regulation is a critical factor for the normal development of the frequency selectivity of cortical neurons and consequently, for the normal development of the tonotopic organization in the auditory cortex.

\section{EXPERIENCE-DEPENDENT AUDITORY PLASTICITY IN ADULTHOOD}

The neocortex mostly reaches maturity after the critical period of development. The specification and functional organization of the neocortex have been shaped into adult form. The neocortex however, does not become static after the critical period. Albeit that the scale of plastic change of the neocortex becomes much smaller during adulthood in comparison with the plasticity during the critical period, the mature neocortex is subject to continuing plastic change because of the ongoing need to adapt to environmental changes. This is another important feature of the sensory cortex.

In the auditory system of adult brains, it is well-known that cortical tonotopic maps are drastically altered following an injury in the auditory periphery. ${ }^{57-59}$ For example, exposure of cats to a loud $6 \mathrm{kHz}$ tone leads to a mild to moderate highfrequency hearing loss bilaterally. In these cats, the tonotopic map of the auditory cortex is largely reorganized. The neurons in the area that originally represented the high frequency lose their high-frequency tuning; they now tune to the highest nondamaged frequency. ${ }^{57} \mathrm{~A}$ similar reorganization of the tonotopic map is also found in the auditory cortex of animals with unilateral lesion of the cochlea. ${ }^{5,59}$ These changes in the auditory cortex clearly demonstrate the ability of the auditory cortex to modify itself and adapt to changes in the input of acoustic information.

This type of auditory plasticity, however, cannot address the most common or fundamental questions. Why may one be more sensitive to one sound but not to another? How does the auditory cortex adapt to the auditory experience or what occurs in the auditory cortex when a biologically important sound is perceived? How does auditory experience or learning modify the auditory cortex?

It has been documented that plastic changes in the central auditory system occur when acoustic signals are repetitively presented and/or are associated with significant biological events through learning. For example, the cortical area that is activated by piano tones is significantly enlarged in musicians compared to control subjects who have never played instruments. ${ }^{60}$ The increase in the area activated by piano tones is probably correlated to the age at which the musician started to practice, ${ }^{60}$ although some questions were raised about the method of statistical analysis used to determine this finding. ${ }^{61}$ Similar results have also been found in monkeys that are trained to discriminate two different frequencies over several weeks. After the successful training, the cortical representation of these frequencies and cortical frequency selectivity are significantly enhanced. ${ }^{62}$ It has also been shown in bats that rapid and repetitive sounds shift the frequency tuning of midbrain neurons toward the frequency of the sound albeit over a small range. ${ }^{63}$ These findings suggest that the auditory cortex enhances the representation of frequently received sounds that are biologically significant.

Classical conditioning, with its use of simple and quantifiable learning patterns, is a good tool for testing various hypotheses. Once the conditioning is established, the animal's behavior shows that the conditioned stimulus, i.e. a given tone has gained behavioural importance. What is the physiological change in the auditory cortex after classical conditioning? Extensive studies by Weinberger and his colleagues have shown that classical conditioning, such as tone-shock pairing, evokes a frequencyspecific change in the frequency tuning of neurons in the primary auditory cortex. ${ }^{9}$ Repeated presentation of a conditioned tone stimulus (CS) paired with an unconditioned shock of foot (US) significantly increases or decreases auditory responses in cortical neurons of adult animals. Following the conditioning, the auditory responses of neurons to non-CS frequencies including the pretraining best frequency are decreased. At the same time, the auditory responses of the neurons to the CS frequency are increased (Figure 3). Due to these frequency-dependent changes in the response magnitudes of cortical neurons to conditioned tones, the CS-US tone-shock conditioning shifts the best frequencies of cortical neurons toward, even to, the frequency of the CS tone after the training. ${ }^{17}$ One may wonder what would occur if a CS tone and US foot-shock are not paired or are delivered randomly. It has been shown that the CS stimuli unpaired with the US increased auditory responses to all frequencies, including a general nonassociative sensitization effect on the auditory responses. ${ }^{64,65}$ This further suggests that the CS-specific changes in the cortical frequency tunings induced by the paired stimuli are the result of learning the toneshock association. The CS-evoked frequency-specific change can be quickly induced in as few as five training trials ${ }^{66}$ and can last for more than two months after tone-foot shock conditioning. ${ }^{67}$ As a result of the shift in the best frequencies of cortical neurons, the representation of the CS-tone frequency is largely enhanced in the auditory cortex. ${ }^{62}$ It is important to note that the CS-specific plasticity evoked by conditioning has the characteristics of associative memory and is not an artifact of arousal or any other factors. Significantly, the CS-specific plasticity in the auditory cortex also develops in instrumental avoidance conditioning and positive rewarding tasks. Furthermore, the expansion of the cortical representation of the CS frequency shows significant correlation with the biological importance of the learnt sound. ${ }^{121}$ These studies are fundamental to understanding learning-induced plasticity or the modification of the frequency identities and the tonotopic map of the auditory cortex. The auditory cortex is able to quickly reorganize itself and maintain this reorganization in order to retain and better 
process the auditory information associated with particular biological events.

Neural mechanisms underlying learning-induced auditory plasticity remain unclear. Since more than one sensory modality is always involved in associative learning, stimuli arriving through two different modalities should theoretically be integrated or associated in the central nervous system. This integration or association should contribute to the plastic changes in the central auditory system. It is shown that the nonlemniscal magnocellular division of the medial geniculate body with the closely associated posterior intralaminar nucleus, external cortex of the inferior colliculus of the midbrain and amygdala are all involved in the integration or association of both auditory (CS) and somatosensory information (US). ${ }^{68-72}$ The integrated or associated information is likely fed back to the auditory system through the cholinergic basal forebrain. Several neural models for learning-induced auditory plasticity have proposed that the cholinergic projections from the nucleus basalis of the basal forebrain to the auditory cortex are a major and final pathway from the non-auditory systems to the auditory system. ${ }^{9,63}$ They contribute significantly to auditory plasticity.

\section{The CHOLINERgiC ROLE IN NEURAL PLASTICITY OF THE ADULT CORTEX}

It is well-known that deficiencies in the cholinergic functioning of the brain (e.g., the basal forebrain) cause severe cognitive decline i.e. Rett Syndrome, ${ }^{73}$ Alzheimer's disease ${ }^{74}$ and age-related memory loss. ${ }^{75}$ Normal cholinergic function is essential for the cognitive processing of the brain.

The general influence of acetylcholine on cortical function appears to be either excitatory or facilitatory. In the frontal cortex, acetylcholine increases the spontaneous firing of the neurons that are either excited or inhibited by conditioning. ${ }^{76}$ In the auditory cortex, micro-iontophoretic administration of acetylcholine to the studied neurons increases both spontaneous discharge and sound evoked responses of these neurons. The rate-level functions of these neurons can be dramatically enhanced by $82 \%$ and their response thresholds reduced by $66 \% .^{77}$ This suggests that external elevation of the cortical acetylcholine level enhances neuronal activities and increases the sensitivity of cortical neurons to sound stimulation. Similar effects on the activities of cortical neurons are also seen when internal acetylcholine of the auditory cortex is increased by the stimulation of the basal forebrain. For example, activation of the basal forebrain produces a long-lasting enhancement of cortical field potentials, neuronal firing rates and EPSPs (excitatory postsynaptic potentials) that are evoked by activation of the auditory thalamus ${ }^{78}$ or by sound. ${ }^{79,80}$ An increased cortical acetylcholine level therefore, promotes the neuronal activities, auditory responses and thalamocortical synaptic transmission of the auditory cortex. This occurs whether or not the acetylcholine is increased internally or externally. Importantly, the general excitatory effects of cortical acetylcholine do not exclude some specific inhibitory effects. For example, cortical application of acetylcholine or agonist increases the auditory responses of cortical neurons to most sound frequencies. However, they also reduce the cortical responses to some other sound frequencies. ${ }^{81-}$ ${ }^{83}$ Such specific cholinergic inhibition is most likely mediated by
GABAergic interneurons ${ }^{84}$ and is possibly important for frequency-specific auditory plasticity in the auditory cortex.

An important question arises as to whether or not the cholinergic facilitation of cortical neurons contributes to learning-induced cortical plasticity that is highly specific to the frequency of learned sound. There are two components to this query; one involves cholinergic facilitation and the other examines the frequency specificity of the plasticity. The frequency specificity is, of course, related to the sound stimulation because the frequency specificity refers to the frequency of conditioned sound. Therefore, we must consider how cortical frequency tuning is modified by the combination of the cortical application of acetylcholine with sound stimulation.

Encouragingly, it has been shown that micro-iontophoresis of acetylcholine or an anticholinesterase agent to cortical neurons induces dramatic changes in the auditory responses of cortical neurons when synchronized with a tone presentation. This change is totally specific to the frequency of the paired tone. ${ }^{81-83}$ This, in turn, strongly suggests that frequency-specific changes in auditory responses of the cortical neurons can simply be induced by direct interaction of cholinergic facilitation and thalamocortical synaptic transmission. One may think that this study solely demonstrates the pharmacological effects of acetylcholine and that it may be unrelated to learning.

What is the role of cortical acetylcholine in learning-induced auditory plasticity? Several recent studies, using the direct application of acetylcholine or its antagonists to the auditory cortex during conditioning, provide some answers. For example, a frequency-specific shift in the cortical best frequency in big brown bats can be induced by the presentation of a tone paired with an electric shock of the leg, i.e., associative conditioning. When acetylcholine is applied to the auditory cortex during the conditioning, this frequency-specific shift is greatly exaggerated and retained for a much longer time. ${ }^{85}$ If atropine, an antagonist of the acetylcholine muscarinic receptor, is applied to the auditory cortex, the tone-shock conditioning is unable to evoke the frequency-specific shift in the frequency tuning of cortical neurons. This study clearly demonstrates that learning cannot evoke neural plasticity in the auditory cortex without the participation of cortical acetylcholine. A recent study on human subjects confirmed these findings in animal experiments. Two groups of subjects received a differential aversive conditioning; one group was given a placebo and the other an anticholinergic drug (scopolamine, $0.4 \mathrm{mg}$ iv) prior to conditioning. The auditory cortex of the subjects was then examined with functional magnetic resonance imaging. The cortical representation of the conditioned tone frequency was exaggerated in subjects that did not take scopolamine but not in subjects taking scopolamine. ${ }^{86}$ These findings suggest that cholinergic modulation of auditory responses of cortical neurons is highly specific as long as it is combined with the sound stimulation. This modulation is important for the frequencyspecific plasticity in the auditory cortex during learning.

When cortical acetylcholine is considered an important agent for learning-induced plasticity in the auditory cortex, the nucleus basalis of the basal forebrain must be addressed. Cholinergic innervation of the cortex mostly originates from the basal forebrain $^{44}$ and, in addition, activation of the basal forebrain enhances activities of cortical neurons and thalamocortical 
synaptic transmission. ${ }^{78-80}$ It has been shown that electrical stimulation of the basal forebrain paired with a tone presentation can produce a large shift in the frequency tuning of cortical neurons toward, even to, the frequency of the paired tone. ${ }^{79,87,88}$ Such a paired stimulation can also evoke a massive reorganization of the frequency map in the auditory cortex centered on the frequency of the paired tone (Figure 4) ${ }^{89}$ As a result, cortical representation of the frequency of the paired tone is greatly enhanced. Importantly, the specific role of the basal forebrain in cortical plasticity is further supported or favored by a recent behavioral study. It demonstrated that the electrical stimulation of the basal forebrain paired with particular sound induces conditioned changes in the activities of both the cardiovascular system and respiratory systems, which is specific to the frequency of the paired sound. ${ }^{90}$ On the other hand, cortical application of atropine can block the facilitation of field potentials ${ }^{78}$ and thus prevent frequency-specific changes evoked by electrical stimulation of the basal forebrain..$^{91}$ The pattern of the frequency-specific plasticity induced by the electrical stimulation of the basal forebrain is the same as that induced by associative learning. Therefore, cholinergic projections of the basal forebrain to the auditory cortex play a crucial role in learning-induced auditory plasticity.

\section{THE ROLE OF MUSCARINIC ACETYLCHOLINE RECEPTORS IN CORTICAL PLASTICITY}

Acetylcholine is known to act on two families of receptors, i.e., muscarinic and nicotine receptors. Compared to the muscarinic receptors, much less is known about the nicotine receptors. Recent studies indicate that the nicotine receptors mediate the cholinergic enhancement of the NMDA (N-methyl$\mathrm{D}$-aspartate) receptor-mediated synaptic transmission during the development of sensory neocortex. ${ }^{92}$ However, the blocking of the nicotine receptor in the immature cortex does not prevent ocular dominance plasticity after eye deprivation. ${ }^{93}$ This indicates that the nicotine receptor may not be involved in the establishment of thalamocortical synaptic connectivity but that it may be involved in later-on refinement or enhancement of thalamocortical synapses.

On the other hand, there is a large body of evidence that indicates the muscarinic receptors mediate most of the cholinergic regulation of brain functions, particularly those of higher mental activities such as learning, memory and cognition. ${ }^{94,95}$ The importance of the muscarinic receptors in cortical response properties and learning-induced auditory plasticity is clearly demonstrated by the fact that atropine, a general antagonist of muscarinic receptors, abolishes almost all cholinergic effects on cortical responses and plasticity. ${ }^{78,81-85,96}$ For example, tetanic stimulation of the basal forebrain can facilitate field potentials, neuronal discharges and excitatory postsynaptic potentials of the auditory cortex in rats evoked by the electrical stimulation of the auditory thalamus. This effect can be abolished by the intracortical administration of atropine. ${ }^{78}$ For auditory learning, application of atropine to the auditory cortex can completely block the frequency-specific shift in frequency tuning of the auditory cortex that is either evoked by tone-shock conditioning ${ }^{85}$ or evoked by electrical stimulation of the basal forebrain paired with tone. ${ }^{91}$ These studies provide convincing evidence that the cholinergic contribution to the auditory plasticity is mostly, if not entirely, mediated by the muscarinic receptor.

Cellular effects of muscarinic receptors also account for the cholinergic regulation of brain function and cortical response properties. Activation of muscarinic receptors increases the excitability of cortical and hippocampal pyramidal neurons through the inhibition of several types of potassium currents ${ }^{97-99}$ Cholinergic activation of pyramidal cells leads to a membrane depolarization. This includes a reduction in the afterhyperpolarization that resulted from the inhibition of calciumactivated potassium current and an induction of slow afterdepolarization. These effects are mediated by muscarinic receptors. ${ }^{99,100}$ Interestingly, in rats trained for odor discrimination, the cortical neurons (olfactory cortex) of animals show reduced after-hyperpolarization currents, which cannot be further reduced by the application of muscarinic agonist carbachol. In contrast, the pseudo-trained animals do not show a reduced after-hyperpolarization current of cortical neurons that can be reduced by the application of carbachol. ${ }^{98}$

Five subtypes of muscarinic ACh receptors (M1-5) have been identified. ${ }^{101-103}$ In the brain, M1, M2 and M4 are the most abundant receptor subtypes and show regional specificity. ${ }^{102}$ The M1 subtype is most abundant in the cerebral cortex while M2 is predominant in the brainstem. ${ }^{101}$ The proportion of other muscarinic subtypes (M3-5) is very low in the cerebral cortex. ${ }^{101}$ These morphological findings implicate the potential importance of the M1 subunit in mediating the cholinergic effects in the cortex. This implication is supported by electrophysiological studies on the auditory cortex of adult animals. As described above, the main effects of cortical administration of acetylcholine are to facilitate the spontaneous discharge and tone-evoked discharge of cortical neurons. However, when acetylcholine is administrated together with the M1 receptor antagonist, pirenzepine, the acetylcholine-mediated facilitation does not take place. In contrast, application of acetylcholine with the M2 receptor antagonist, gallamine, still induces increases in spontaneous discharge and tone-evoked discharge. ${ }^{77}$ Gathered from morphological and physiological studies, these findings strongly suggest that acetylcholine facilitates the auditory responses of cortical neurons predominantly via the M1 subtype but not the M2 or any other subtypes.

Our understanding of the contribution of muscarinic receptors, including the M1 subtype, to the specification of the auditory cortex during early development remains poor. Studies in the development of the visual cortex, however, provide strong evidence that muscarinic receptors are important to the development of cortical ocular dominance. Ocular dominance plasticity, first reported by Wiesel and Hubel, ${ }^{35}$ is considered a good example of the plasticity of the visual cortex. During development, synaptic competition of thalamocortical afferents from both eyes plays a critical role in organization of ocular dominance in the visual cortex. The formation of the ocular dominance in the visual cortex is strongly influenced, i.e., cortical neurons lose the response to the deprived eye and the ocular dominance is biased to the normal eye if only one eye is deprived during the critical period of development. ${ }^{35,104}$ Importantly, the ocular dominance plasticity can also be eliminated by blocking muscarinic receptors but not by blocking 
nicotine receptors. ${ }^{93}$ This suggests that the cortical muscarinic receptors are critical for early development of the cortex. It is further shown that this muscarinic-dependent cortical plasticity is mediated by the M1 subtype but not the M2 subtype..$^{93,105}$

Studies of the distribution of muscarinic receptor subtypes throughout the neocortex during early life have also yielded some information. In mice, the M1-3 receptors can be detected in the neonatal cerebral cortex. ${ }^{106}$ Notably, the dynamic period of development of cortical muscarinic receptors dramatically coincides with the onset of cholinergic activity. ${ }^{18,107}$ Each receptor displays specific changes, such as transient appearance, in the cortical region during early development. The M1 receptor is of particular interest once again because its transient appearance pattern is associated with the critical period of cortical development, i.e., the period of thalamocortical entry and synapse formation. ${ }^{106}$

In conclusion, these studies on the plasticity of visual cortex and the ontogeny of muscarinic receptors during early development reveal that the M1 receptor appears to be the most important of the receptors. At the very least, the M1-3 muscarinic receptors may be involved in early postnatal development of the cortex. The auditory cortex likely shares the muscarinic mechanisms with the visual cortex and other neocortical areas.

\section{ROLE OF CORTICOFUGAL PROJECTIONS IN THE CORTICAL} DEVELOPMENT AND PLASTICITY

The final issue in this review addresses why experiencedependent auditory plasticity is highly specific to sound frequency. It is perhaps obvious that auditory responses of neurons that tune to the frequency of a learned sound are facilitated during learning. ${ }^{9}$ However, why is the frequency tuning of cortical neurons that do not tune to the frequency of the learned sound able to shift toward, even to, the learned frequency? The answer will not likely be found in nonauditory systems such as the cholinergic basal forebrain since they do not carry auditory information.

Recent progress in corticofugal modulation by Suga and his colleagues $^{13,19}$ unveils a crucial neural mechanism for the frequency-specific auditory plasticity. The intriguing aspect of corticofugal modulation is its feature-specificity. For example, the corticofugal modulation is specific to the best frequency in frequency-tuned neurons of bats and rodents. ${ }^{108-110}$ A type of specialized neuron, called delay-tuned neurons, tune to the time delay of the echoes from the emitted pulses and are suited for distance measurement in the mustached bat. ${ }^{111,112}$ For these neurons, corticofugal modulation is specific to the best echo delay instead of the best frequency. ${ }^{19,113}$ The general role of corticofugal modulation in auditory information processing and plasticity has been demonstrated in various animal studies. Although the corticofugal modulation exhibits species-specific variations, a common point is that in non-specialized neurons, the focal activation of cortical neurons facilitates the auditory responses of cortical and subcortical neurons that tune to the same frequency. ${ }^{109,110,114}$ At the same time, it inhibits auditory responses and shifts frequency tuning of subcortical neurons with different frequencies toward the best frequency of the activated cortical neurons ${ }^{109,110}$ (Figure 5). We have called this corticofugal modulation or adjustment "egocentric selection"113 and the result of corticofugal adjustment "center-surround"109 plasticity. The corticofugal system therefore, mediates auditory plasticity through a highly focused positive feedback to physiologically "matched" subcortical neurons together with widespread lateral inhibition to physiologically "unmatched" subcortical neurons. ${ }^{13,19}$ Importantly, the cortical activation results in such feature-specific plasticity in not only the subcortical nuclei ${ }^{109,110}$ but also in the auditory cortex. ${ }^{114}$ This suggests that cortical activation elicits plasticity in the central auditory system, at least in the midbrain, thalamus and cortex through corticofugal projections incorporation with ascending projections, i.e., feedback loops. As a result of corticofugal modulation, cortical and subcortical representation of the frequency is largely enhanced. ${ }^{13,110,114,115}$ Notably, the pattern or direction of the shift in frequency tuning of unmatched neurons evoked by focally cortical activation is identical to that evoked by auditory learning. ${ }^{63,66,110,115}$ These findings strongly suggest that the corticofugal modulation incorporated with ascending innervation is an intrinsic mechanism underlying frequencyspecific plasticity in the auditory system.

Significantly, auditory learning induces frequency-specific plasticity not only in the auditory cortex but also in the subcortical nuclei such as the midbrain ${ }^{63}$ and thalamus. ${ }^{69}$ One may argue that the auditory cortex passively receives the plastic changes in the subcortical nuclei or the auditory cortex actively instructs the plasticity in the subcortical nuclei. It has been recently found that the frequency-specific shift in the midbrain evoked by tone-shock associative learning can be augmented by cortical application of acetylcholine and reduced by cortical application of atropine, the antagonist of muscarinic acetylcholine receptors. ${ }^{85}$ This finding partially suggests that the auditory cortex plays an active role in subcortical plasticity during learning via corticofugal modulation. This argument warrants some clarification.

Corticofugal modulation occurs surprisingly early in life. Histological studies show that corticothalamic fibers establish connections with the thalamus at the same time that thalamocortical fibers start to innervate the cortical neurons, e.g., embryonic day 15 in mice. ${ }^{116}$ It has been speculated that corticothalamic projection may play an important role in developing early specification and identity of the visual cortex before the critical period of development. ${ }^{29}$

In conclusion, corticofugal modulation is strongly and actively involved in the dynamic changes of the auditory cortex throughout life.

\section{A HYPOTHETIC CORE OF NEURAL CIRCUITRY FOR CORTICAL DEVELOPMENT AND PLASTICITY}

As discussed above, thalamocortical, cholinergic and corticofugal projections are three critical factors influencing the plasticity of the auditory cortex during both early development and adulthood. These three projections are anatomically connected or associated at the auditory cortex. Since both the ascending and descending (corticofugal) projections are tonotopically organized, ${ }^{117-120}$ corticofugal modulation is highly specific in frequency. Therefore, the corticofugal projections apparently form point-to-point frequency-specific feedback loops. The cholinergic projection of the basal forebrain acts 
directly on the loops at the auditory cortex as shown in Figure 1. This particular neural circuit could be a core of neural substrates for the development and plasticity of cortical specification and identities such as the frequency tuning of cortical neurons. In this circuit, the tonotopic cortico-subcortical loops execute the frequency-specific plasticity and cholinergic projections function as an accelerator or amplifier., 913,19

This hypothetic core circuit is able to interpret the plastic changes in the auditory cortex from the perinatal period to adulthood. Within the cortico-subcortical loops, any perceived sound tends to enhance the central representation of itself in a "center-surround" manner through the "egocentric selection". If a particular sound is more frequently received by an animal, the egocentric selection will occur in its central auditory system and result in the "center-surround" plasticity or reorganization so that the contrast of neural representation of this sound will be increased or enhanced. On the other hand, if one input channel is eliminated such as through restricted cochlear deprivation for example, the normal channel neighboring to this deprived channel will be relatively stronger. In this case, the frequency tuning of the neurons in the input-deprived loops will be shifted to the frequency tuning of this normal loop. However, this circuit is typically very weak; it may only elicit very small degrees of the "center-surround" plasticity, particularly in adulthood. If cortical acetylcholine is increased or the cholinergic neurons in the basal forebrain are activated for any reason, the cortical neurons in this circuit as well as the entire corticofugal feedback loop will be impacted or facilitated. Thus the "egocentric selection" will be enhanced and the "center-surround" plasticity will be markedly increased to be noticeable or detectable. It is also predictable that facilitation of any site in the corticofugal feedback loop will enhance the "center-surround" plasticity (Figure 5). In contrast, a decrease in cortical acetylcholine as seen in Rett Syndrome, Alzheimer's disease and aging would reduce the power of "egocentric selection". The "centersurround" plasticity would be less likely to develop and would result in deficits in auditory cognition.

\section{SUMMARY}

One of the most intriguing features of the cerebral cortex is its parcellation or division into distinct functional areas. The thalamocortical afferents instruct the quick maturation of the specification and functional identities of each specific cortical area such as the frequency tuning of cortical neurons and frequency representation of the auditory cortex.

Yet another important feature of the cerebral cortex is its experience-dependent plasticity that is feature-specific. The thalamocortical afferents are also a key factor in sending environmental information to the cortex and instructing any accompanying plastic changes.

In both the development and the learning-induced plasticity of the auditory cortex, the cholinergic modulation of the auditory cortex is crucial. It acts as a permissive factor for the normal development of the cortex and for the distinct plasticity in the auditory cortex. The cholinergic function in the auditory cortex is predominantly mediated by the muscarinic acetylcholine receptor, specifically, subtype 1 .

Finally, corticofugal modulation appears to be a very important mechanism intrinsic to the auditory system for the early develop- ment of cortical specification and feature-specific plasticity. It appears to have an impact throughout the entire life cycle.

The thalamocortical, cholinergic and corticofugal projections are hypothesized to organize the neural circuit that is crucial to cortical development and plasticity.

\section{ACKNOWLEDGEMENTS}

I thank Dr. N. Suga and Dr. J. J. Eggermont for their helpful comments on this manuscript; and Ms. B. Zochodne for her editorial assistance. This work is supported by the INMHA of the Canadian Institute of Health Research and the Alberta Heritage Foundation for Medical Research.

\section{REFERENCES}

1. Dreher B, Burke W, Calford MB. Cortical plasticity revealed by circumscribed retinal lesions or artificial scotomas. Prog Brain Res 2001; 134:217-246.

2. Eggermont JJ. Representation of spectral and temporal sound features in three cortical fields of the cat. Similarities outweigh differences. J Neurophysiol 1998; 80:2743-2764.

3. Stiebler I, Neulist R, Fichtel I, Ehret G. The auditory cortex of the house mouse: left-right differences, tonotopic organization and quantitative analysis of frequency representation. J Comp Physiol [A] 1997;181(6):559-571.

4. Fox K, Glazewski S, Schulze S. Plasticity and stability of somatosensory maps in thalamus and cortex. Curr Opin Neurobiol 2000; 10(4):494-497.

5. Phillips DP, Judge PW, Kelly JB. Primary auditory cortex in the ferret (Mustela putorius): neural response properties and topographic organization. Brain Res 1988; 443(1-2):281-294.

6. Suga N. Multi-function theory for cortical processing of auditory information: implications of single-unit and lesion data for future research. J Comp Physiol [A] 1994; 175:135-144.

7. Irvine DR, Rajan R. Injury- and use-related plasticity in the primary sensory cortex of adult mammals: possible relationship to perceptual learning. Clin Exp Pharmacol Physiol 1996; 23(1011):939-947.

8. Scheich H, Stark H, Zuschratter W, Ohl FW, Simonis CE. Some functions of primary auditory cortex in learning and memory formation. Adv Neurol 1997; 73:179-193.

9. Weinberger NM. Physiological Memory in Primary Auditory Cortex: Characteristics and Mechanisms. Neurobiol Learn Mem 1998; 70:226-251.

10. Edeline JM. Learning-induced physiological plasticity in the thalamo-cortical sensory systems: a critical evaluation of receptive field plasticity, map changes and their potential mechanisms. Prog Neurobiol 1999; 57(2):165-224.

11. Kilgard MP, Pandya PK, Engineer ND, Moucha R. Cortical network reorganization guided by sensory input features. Biol Cybern 2002; 87(5-6):333-343.

12. Rauschecker JP. Cortical map plasticity in animals and humans. Prog Brain Res 2002; 138:73-88.

13. Suga N, Xiao Z, Ma X, Ji W. Plasticity and corticofugal modulation for hearing in adult animals. Neuron 2002; 36(1):918.

14. Rubenstein JL. Intrinsic and extrinsic control of cortical development. Novartis Found Symp 2000; 228:67-75.

15. Rubenstein JL, Rakic P. Genetic control of cortical development. Cereb Cortex 1999; 9:521-523.

16. Chapman B, Godecke I, Bonhoeffer T. Development of orientation preference in the mammalian visual cortex. J Neurobiol 1999; 41:18-24.

17. Bakin JS, Weinberger NM. Classical conditioning induces CSspecific receptive field plasticity in the auditory cortex of the guinea pig. Brain Res 1990; 536:271-286.

18. Hohmann CF, Berger-Sweeney J. Cholinergic regulation of cortical development and plasticity: New twist to an old story. Perspect Dev Neurobiol 1998; 5:401-425.

19. Suga N, Yan J, Zhang Y. Cortical maps for hearing and egocentric 
selection for self-organization. Trends Cognit Sci 1997; 1:1-14.

20. Berard N, Pizzorusso T, Maffei L. Critical period during sensory development. Curr Opin Neurobiol 2000; 10:138-145.

21. Eggermont JJ. Differential maturation rates for response parameters in cat primary auditory cortex. Auditory Neurosci 1996; 2:309-327.

22. Harwerth RS, Smith EL 3rd, Duncan GC, Crawford ML, von Noorden GK. Multiple sensitive periods in the development of the primate visual system. Science 1986; 232:235-238.

23. Molnar Z, Lopez-Bendito G, Small J, Partridge LD, Blakemore C, Wilson MC. Normal development of embryonic thalamocortical connectivity in the absence of evoked synaptic activity. J Neurosci 2002;22(23):10313-10323.

24. Crandall JE, Caviness VS Jr. Thalamocortical connections in newborn mice. J Comp Neurol 1984; 228:542-556.

25. Erzurumlu RS, Jhaveri S. Emergence of connectivity in the embryonic rat parietal cortex. Cereb Cortex 1992; 2(4):336-352.

26. Miyashita-Lin EM, Hevner R, Wassarman KM, Martinez S, Rubenstein JL. Early neocortical regionalization in the absence of thalamic innervation. Science 1999; 285:906-909.

27. Nakagawa Y, Johnson JE, O'Leary DD. Graded and areal expression patterns of regulatory genes and cadherins in embryonic neocortex independent of thalamocortical input. $\mathbf{J}$ Neurosci 1999; 19:10877-10885.

28. O'Leary DD, Nakagawa Y. Patterning centers, regulatory genes and extrinsic mechanisms controlling arealization of the neocortex. Curr Opin Neurobiol 2002; 12:14-25.

29. Yuste R, Sur M. Development and plasticity of the cerebral cortex: from molecules and maps. J Neurobiol 1999; 41:1-6.

30. Harrison RV, Nagasawa A, Smith DW, Stanton S, Mount RJ. Reorganization of auditory cortex after neonatal high frequency cochlear hearing loss. Hear Res 1991; 54(1):11-19.

31. Harrison RV, Stanton SG, Ibrahim D, Nagasawa A, Mount RJ. Neonatal cochlear hearing loss results in developmental abnormalities of the central auditory pathways. Acta Otolaryngol 1993; 113(3):296-302.

32. Stanton SG, Harrison RV. Neonatal auditory augmentation modifies cochleotopic mapping in primary auditory cortex of the cat. Auditory Neurosci 1996; 2: 97-107.

33. Zhang LI, Bao S, Merzenich MM. Persistent and specific influences of early acoustic environments on primary auditory cortex. Nat Neurosci 2001; 4(11):1123-1130.

34. Zhang LI, Bao S, Merzenich MM. Disruption of primary auditory cortex by synchronous auditory inputs during a critical period. Proc Natl Acad Sci USA 2002; 99(4):2309-2314.

35. Wiesel TN, Hubel DH. Single-cell responses in striate cortex of kittens deprived of vision in one eye. J Neurophysiol 1963; 26:1003-1017.

36. Stanton SG, Harrison RV. Projections from the medial geniculate body to primary auditory cortex in neonatally deafened cats. $\mathrm{J}$ Comp Neurol 2000; 426(1):117-129.

37. Harrison RV, Ibrahim D, Mount RJ. Plasticity of tonotopic maps in auditory midbrain following partial cochlear damage in the developing chinchilla. Exp Brain Res 1998; 123(4):449-460.

38. Poon PW, Chen X, Postnatal exposure to tones alters the tuning characteristics of inferior collicular neurons in the rat. Brain Res 1992; 586:391-394.

39. Gao W, Pallas SL. Cross-modal reorganization of horizontal connectivity in auditory cortex without altering thalamocortical projections. J Neurosci 1999; 19(18):7940-7950.

40. Sharma J, Angelucci A, Sur M. Induction of visual orientation modules in auditory cortex. Nature 2000;404(6780):841-847.

41. Robertson RT, Gallardo KA, Claytor KJ, et al. Neonatal treatment with 192 IgG-saporin produces long-term forebrain cholinergic deficits and reduces dendritic branching and spine density of neocortical pyramidal neurons. Cereb Cortex 1998; 8(2):142-155.

42. Zhu XO, de Permentier PJ, Waite PM. Cholinergic depletion by IgG192-saporin retards development of rat barrel cortex. Brain Res Dev Brain Res 2002; 136(1):1-16.

43. Mesulam MM, Mufson EJ, Levey AI, Wainer BH. Cholinergic innervation of cortex by the basal forebrain: cytochemistry and cortical connections of the septal area, diagonal band nuclei, nucleus basalis (substantia innominata), and hypothalamus in the rhesus monkey. J Comp Neurol 1983; 214(2):170-197.

44. Mesulam MM, Mufson EJ, Wainer BH, Levey AI. Central cholinergic pathways in the rat: an overview based on an alternative nomenclature (Ch1-Ch6). Neuroscience 1983; 10:1186-1201.

45. Houser CR, Crawford GD, Salvaterra PM, Voughn JE. Immunocytochemical localization of cholineacetyltransferase in rat cerebral cortex: a study of cholinergic neurons and synapses. J Comp Neurol 1985; 243:17-34.

46. Kitt CA, Hohmann CF, Coyle JT, Price DL. Cholinergic innervation of mouse forebrain structures. J Comp Neurol 1994; 341:117-129.

47. Mechawar N, Descarries L. The cholinergic innervation develops early and rapidly in the rat cerebral cortex: a quantitative immunocytochemical study. Neurosci 2001; 108(4):555-567.

48. Hohmann CF, Ebner FF. Development of cholinergic markers in mouse forebrain. I. Choline acetyltransferase enzyme activity and acetylcholinesterase histochemistry. Brain Res 1985; 355(2):225-241

49. Kristt DA. Development of neocortical circuitry: histochemical localization of acetylcholinesterase in relation to the cell layers of rat somatosensory cortex. J Comp Neurol 1979; 186(1):1-15.

50. Thal LJ, Gilbertson E, Armstrong DM, Gage FH. Development of the basal forebrain cholinergic system: phenotype expression prior to target innervation. Neurobiol Aging 1992; 13(1):67-72.

51. Virgili M, Contestabile A, Barnabei O. Postnatal maturation of cholinergic markers in forebrain regions of C57BL/6 mice. Brain Res Dev Brain Res 1991; 63(1-2):281-285.

52. Zahalka EA, Seidler FJ, Lappi SE, Yanai J, Slotkin TA. Differential development of cholinergic nerve terminal markers in rat brain regions: implications for nerve terminal density, impulse activity and specific gene expression. Brain Res 1993; 601(1-2):221-229.

53. Hohmann CF, Brooks AR, Coyle JT. Neonatal lesions of the basal forebrain cholinergic neurons result in abnormal cortical development. Brain Res 1988; 470(2):253-264.

54. Hohmann CF, Kwiterovich KK, Oster-Granite ML, Coyle JT. Newborn basal forebrain lesions disrupt cortical cytodifferentiation as visualized by rapid Golgi staining. Cereb Cortex 1991; 1(2):143-157.

55. Torres EM, Perry TA, Blockland A, et al. Behavioural, histochemical and biochemical consequences of selective immunolesions in discrete regions of the basal forebrain cholinergic system. Neurosci 1994; 63(1):95-122.

56. Robertson RT, Mostamand F, Kageyama GH, Gallardo KA, Yu J. Primary auditory cortex in the rat: transient expression of acetylcholinesterase activity in developing geniculocortical projections. Brain Res Dev Brain Res 1991; 58(1):81-95.

57. Eggermont JJ, Komiya H. Moderate noise trauma in juvenile cats results in profound cortical topographic map changes in adulthood. Hear Res 2000; 142(1-2):89-101.

58. Robertson D, Irvine DR. Plasticity of frequency organization in auditory cortex of guinea pigs with partial unilateral deafness. J Comp Neurol 1989; 282(3):456-471.

59. Rajan R, Irvine DR, Wise LZ, Heil P. Effect of unilateral partial cochlear lesions in adult cats on the representation of lesioned and unlesioned cochlea in primary auditory cortex. J Comp Neurol 1993; 338(1):17-49.

60. Pantev C, Oostenveld R, Engelien A, et al. Increased auditory cortical representation in musicians. Nature 1998; 392:811-814.

61. Monaghan P, Metcalfe NB, Ruxton GD. Does practice shape the brain? Nature 1998; 394(6692):434.

62. Recanzone GH, Schreiner CE, Merzenich MM. Plasticity in the frequency representation of primary auditory cortex following discrimination training in adult owl monkeys. J Neurosci 1993;13(1):87-103.

63. Gao E, Suga N. Experience-dependent corticofugal adjustment of midbrain frequency map in bat auditory system. Proc Natl Acad Sci USA 1998; 95:12663-12670.

64. Bakin JS, Lepan B, Weinberger NM. Sensitization induced receptive field plasticity in the auditory cortex is independent of CS-modality. Brain Res 1992; 577:226-235. 
65. Edeline J-M, Weinberger NM. Receptive field plasticity in the auditory cortex during frequency discrimination training: selective returning independent of task difficulty. Behav Neurosci 1993; 107:82-103.

66. Edeline J-M, Pham P, Weinberger NM. Rapid development of learning-induced receptive field plasticity in the auditory cortex. Behav Neurosci 1993;107:539-557.

67. Weinberger NM, Javid R, Lepan B. Long-term retention of learning-induced receptive-field plasticity in the auditory cortex. Proc Natl Acad Sci USA 1993; 90:2394-2398.

68. Edeline J-M, Dutrieux G, Neuenschwander-EI, Massioui N. Multiunit changes in hippocampus and medial geniculate body in free-behaving rats during acquisition and retention of a conditioned response to a tone. Behav Neural Biol 1988; 50:61-79.

69. Edeline J-M, Weinberger NM. Associative retuning in the thalamic source of input to the amygdala and auditory cortex: receptive field plasticity in the medial division of the medial geniculate body. Behav Neurosci 1992; 106:81-105.

70. Feldman DE, Knudsen EI. Pharmacological specialization of learned auditory responses in the inferior colliculus of the barn owl. J Neurosci 1998; 18(8):3073-3087.

71. McKernan MG, Shinnick-Gallagher P. Fear conditioning induces a lasting potentiation of synaptic currents in vitro. Nature 1997; 390:607-611.

72. Rogan MT, Staubli UV, LeDoux JE. Fear conditioning induces associative long-term potentiation in the amygdala. Nature 1997; 390:604-607.

73. Armstrong DD. Rett syndrome neuropathology review 2000. Brain Dev 2001; 23(Suppl 1):S72-S76.

74. Frolich L. The cholinergic pathology in Alzheimer's disease-discrepancies between clinical experience and pathophysiological findings. J Neural Transm 2002; 109(7-8): 1003-1013.

75. Gallagher M, Colombo PJ. Aging: the cholinergic hypothesis of cognitive decline. Curr Opin Neurobiol 1995; 5:161-168.

76. Pirch JH, Turco K, Rucker HK. A role for acetylcholine in conditioning-related responses of rat frontal cortex neurons: microiontophoretic evidence. Brain Res 1992;586(1):19-26.

77. Metherate R, Ashe JH, Weinberger NM. Acetylcholine modifies neuronal acoustic rate-level functions in guinea pig auditory cortex by an action at muscarinic receptors. Synapse 1990; 6:364-368.

78. Metherate R, Ashe JH. Nucleus basalis stimulation facilitates thalamocortical synaptic transmission in the rat auditory cortex. Synapse 1993; 14:132-143

79. Edeline J-M, Hars B, Maho C, Hennevin E. Transient and prolonged facilitation of tone-evoked responses induced by basal forebrain stimulations in the rat auditory cortex. Exp Brain Res 1994; 97:373-386.

80. Hars B, Maho C, Edeline J-M, Hennevin E. Basal forebrain stimulation facilitates tone-evoked responses in the auditory cortex of awake rat. Neurosci 1993; 56(1):61-74.

81. Ashe JH, McKenna TM, Weinberger NM. Cholinergic modulation of frequency receptive fields in auditory cortex: II. Frequencyspecific effects of anticholinesterases provide evidence for a modulatory action of endogenous ACh. Synapse 1989; 4:44-54.

82. McKenna TM, Ashe JH, Weinberger NM. Cholinergic modulation of frequency receptive fields in auditory cortex: I. Frequencyspecific effects of muscarinic agonists. Synapse 1989; 4:30-43.

83. Metherate R, Weinberger NM. Acetylcholine produces stimulusspecific receptive field alterations in cat auditory cortex. Brain Res 1989; 480:372-377.

84. Bandrowski AE, Moore SI. Ashe JH. Cholinergic synaptic potentials in the superagranular layers of auditory cortex. Synapse 2001; 41:118-130

85. Ji W, Gao E, Suga N. Effects of acetylcholine and atropine on plasticity of central auditory neurons caused by conditioning in bats. J Neurophysiol 2001; 86:211-225.

86. Thiel CM, Friston KJ, Dolan RJ. Cholinergic modulation of experience-dependent plasticity in human auditory cortex. Neuron 2002; 35(3):567-574.

87. Bjordahl TS, Dimyan MA, Weinberger NM. Induction of longterm receptive field plasticity in the auditory cortex of the waking guinea pig by stimulation of the nucleus basalis. Behav Neurosci 1998; 112(3):1-13.

88. Dimyan MA, Weinberger NM. Basal forebrain stimulation induces discriminative receptive field plasticity in the auditory cortex. Behav Neurosci 1999; 113(4):691-702.

89. Kilgard MP, Merzenich MM. Cortical map reorganization enabled by nucleus basalis activity. Science 1998; 279:1714-1718.

90. McLin DE 3rd, Miasnikov AA, Weinberger NM. Induction of behavioral associative memory by stimulation of the nucleus basalis. Proc Natl Acad Sci USA 2002; 99(6):4002-4007.

91. Miasnikov AA, McLin DE 3rd, Weinberger NM. Muscarinic dependence of nucleus basalis induced conditioned receptive field plasticity. Neuroreport 2001; 12(7):1537-1542.

92. Aramakis VB, Metherate R. Nicotine selectively enhances NMDA receptor-mediated synaptic transmission during postnatal development in sensory neocortex. J Neurosci 1998; 18(20):8485-8495.

93. Gu Q, Singer W. Effects of intracortical infusion of anticholinergic drugs on neuronal plasticity in kitten striate cortex. Eur J Neurosci 1993; 5(5):475-485.

94. Brown JH, Taylor P. Muscarinic receptor agonists and antagonists. In: Hardman JG, Limbrid LE, (Eds). The Pharmacological Basis of Therapeutic, ed 9, New York: McGraw-Hill, 1996; 141-160.

95. Wess J, Buhl T, Lambrecht G, Mutschler E. Cholinergic receptors. In: Emmett J, (Ed). Comprehensive Medicinal Chemistry, Vol. 3, Oxford: Pergamon, 1990; 423-491.

96. Bakin JS, Weinberger NM. Induction of a physiological memory in the cerebral cortex by stimulation of the nucleus basalis. Proc Natl Acad Sci USA 1996; 93(20):11219-11224.

97. Krnjevic K. Central cholinergic mechanisms and function. Prog Brain Res 1993; 98:285-292.

98. Saar D, Grossman Y, Barkai E. Long-lasting cholinergic modulation underlies rule learning in rats. J Neurosci 2001; 21(4):1385-1392.

99. Rouse ST, Hamilton SE, Potter LT, Nathanson NM, Conn PJ. Muscarinic-induced modulation of potassium conductances is unchanged in mouse hippocampal pyramidal cells that lack functional M1 receptors. Neurosci Lett 2000; 278(1-2):61-64

100. Haj-Dahmane S, Andrade R. Ionic mechanism of the slow afterdepolarization induced by muscarinic receptor activation in rat prefrontal cortex. J Neurophysiol 1998; 80(3):1197-1210.

101. Levey AI. Immunological localization of M1-M5 muscarinic acetylcholine receptors in peripheral tissues and brain. Life Sci 1993; 52:441-448.

102. Levey AI, Kitt CA, Simonds WF, Price DL, Brann MR. Identification and localization of muscarinic acetylcholine receptor proteins in brain with subtype-specific antibodies. J Neurosci 1991; 11:3218-3226.

103. Rotter T. The molecular basis of muscarinic receptor diversity. Trends Neurosci 1989; 12:148-151.

104. Gordon JA, Stryker MP. Experience-dependent plasticity of binocular responses in the primary visual cortex of the mouse. J Neurosci 1996; 16(10):3274-3286.

105. Gu Q. Neuromodulatory transmitter systems in the cortex and their role in cortical plasticity. Neurosci 2002; 111(4):815-835.

106. Hohmann CF, Potter ED, Levey AI. Development of muscarinic receptor subtypes in the forebrain of the mouse. J Comp Neurol 1995; 358(1):88-101.

107. Tan XX, Costa LG. Postnatal development of muscarinic receptorstimulated phosphoinositide metabolism in mouse cerebral cortex: sensitivity to ethanol. Brain Res Dev Brain Res 1995; 86(1-2):348-353.

108. Zhang Y, Suga N, Yan J. Corticofugal modulation of frequencyprocessing in bats auditory system. Nature 1997; 387:900-903.

109. Yan J, Ehret G. Corticofugal modulation of midbrain sound processing in the house mouse. Eur J Neurosci 2002; 16(1):119-128.

110. Yan W, Suga N. Corticofugal modulation of the midbrain frequency map in the bat auditory system. Nat Neurosci 1998; $1: 54-58$.

111. Suga N, O'Neill WE. Neural axis representing target range in the auditory cortex of the mustache bat. Science 1979; 206(4416):351-353 
112. Yan J, Suga N. The midbrain creates and the thalamus sharpens echo-delay tuning for the cortical representation of targetdistance information in the mustached bat. Hear Res 1996; 93(12):102-110.

113. Yan J, Suga N. Corticofugal modulation of time-domain processing of biosonar information in bats. Science 1996; 273:1100-1103.

114. Sakai M, Suga N. Centripetal and centrifugal reorganizations of frequency map of auditory cortex in gerbils. Proc Natl Acad Sci USA 2002; 99(10):7108-7112.

115. Yan J, Ehret G. Corticofugal reorganization of midbrain tonotopic map in mice. Neuroreport 2001; 12(15):3313-3316.

116. Auladell C, Perez-Sust P, Super H, Soriano E. The early development of thalamocortical and corticothalamic projections in the mouse. Anat Embryol 2000; 201(3):169-179.

117. Winer JA. The functional architecture of the medial geniculate body and the primary auditory cortex. In: Webster DB, Popper AN, Fay RR, (Eds). The Mammalian Auditory Pathway:
Neuroanatomy. New York: Springer-Verlag, 1992: 222-409.

118. Andersen RA, Synder RL, Merzenich MM, The topographic organization of corticocollicular projections from physiologically identified loci in the AI, AII, and anterior auditory cortical field of the cat. J Comp Neurol 1980; 191:479-494.

119. Herbert H, Aschoff A, Ostwald J. Topography of projections from the auditory cortex to the inferior colliculus in the rat. J Comp Neurol 1991; 304:103-122.

120. Saldana E, Feliciano M, Mugnaini E. Distribution of descending projections from primary auditory neocortex to inferior colliculus mimics the topography of intracollicular projections. J Comp Neurol 1996; 371:15-40.

121. Rutkowski RG, Than K., Weinberger NM, Evidence for area of frequency representation encoding acquired stimulus importance in rat primary auditory cortex. Program No. 80.3. 2002 Abstract Viewer/Itinerary Planner. Washington, DC: Society for Neuroscience, 2002. Online. 